\title{
Relationship between risk factors for infertility in women and lead, cadmium, and arsenic blood levels: a cross-sectional study from Taiwan
}

Hsiao-Ling Lei ${ }^{1}$, Hsiao-Jui Wei ${ }^{2,3}$, Hsin-Yi Ho ${ }^{2,3}$, Kai-Wei Liao ${ }^{1}$ and Ling-Chu Chien ${ }^{1 *}$

\begin{abstract}
Background: The World Health Organization reported that more than $10 \%$ of women are severely affected by infertility, making the condition a major worldwide public health problem. Lead (Pb), cadmium (Cd), and arsenic (As) are environmental pollutants that may contribute to reproductive disorders. This cross-sectional study investigated the association between blood concentrations of $\mathrm{Pb}, \mathrm{Cd}$, and $\mathrm{As}$ and risk factors for infertility in women.

Methods: Women who were infertile $(N=310)$ or pregnant $(N=57)$ were recruited from the gynecology and obstetrics department of a hospital. The participants were interviewed to obtain their sociodemographic, reproductive, and lifestyle information. The concentrations of $\mathrm{Pb}, \mathrm{Cd}$, and $\mathrm{As}$ in their blood samples were measured using inductively coupled plasma mass spectrometry.

Results: Our findings suggested that the concentrations of $\mathrm{Pb}$ and $\mathrm{As}$, but not $\mathrm{Cd}$, were significantly higher in the blood of infertile women than in that of pregnant women. A higher percentage of the infertile women consumed more alcohol, used Chinese herbal medicine more frequently, and lacked physical activity compared with the pregnant women. After accounting for potentially relevant predictors, we observed that blood Pb levels might be elevated by using Chinese herbal medicine 1-6 times per week ( $\mathrm{aOR}=2.82, p=0.05)$. In addition, engaging in physical activity $1-2$ times per week $(\mathrm{aOR}=0.37, p=0.05)$ might assist in reducing $\mathrm{Pb}$ accumulation in infertile women, though the $\mathrm{p}$ value was borderline.

Conclusions: Lack of physical activity and frequent use of Chinese herbal medicine may be associated with elevated blood Pb levels in infertile women. Chinese herbal medicine use was observed to increase the Pb body burden of both infertile and pregnant women in this study. The risk-benefit for Chinese herbal medicine intake should be evaluated by women of childbearing age.
\end{abstract}

Keywords: Lead, Cadmium, Arsenic, Female infertility, Chinese herbal medicine

\footnotetext{
* Correspondence: Icchien@tmu.edu.tw

${ }^{1}$ School of Public Health, Taipei Medical University, No. 250, Wuxing St.,

Taipei City 110, Taiwan

Full list of author information is available at the end of the article
} 


\section{Background}

The World Health Organization [1] reported that more than $10 \%$ of women are severely affected by infertility. The reproductive health of women of childbearing age is currently a major worldwide public health problem. An increasing number of researchers acknowledge the influence of environmental pollutants, such as heavy metals, organic hydrocarbons, and pesticides from various sources, on public health, particularly in reproductive disorders. Environmental factors, such as exposure to heavy metals, can cause reproductive dysfunction in women [2]; even trace exposure to toxic metals may affect the reproductive health of women [3]. Several studies have illustrated the adverse effects of heavy metals in utero, and the potential reproductive toxicity of these pollutants at levels lower than the tolerable/acceptable daily intake values (ADI) is of serious concern [4-7]. Toxic metals may induce hormonal changes affecting the menstrual cycle, ovulation, and female fertility [8].

Mattison [9] indicated that the impact of environmental pollutants on pregnancy outcomes might have no threshold level, and that the only reasonable approach is to minimize exposures for everyone. Nonessential metals, including lead $(\mathrm{Pb})$, cadmium $(\mathrm{Cd})$, and arsenic (As), are reproductive toxicants widely distributed in the environment [10]. Several epidemiologic studies on menstruation have indicated that metals affect hormone levels [2, 11-14]. $\mathrm{Pb}$ and $\mathrm{Cd}$ have been identified in human follicular fluid [15-18] and As was shown to cause dose-related increases in ovarian tumors [19]. Randolph et al. [20] reported that women whose infertility could not be otherwise explained may have decreased ovarian sensitivity to gonadotropins, resulting in higher circulating gonadotropin levels, including higher mean serum FSH and LH levels. High levels of serum FSH could indicate poor ovarian function. Krieg [12] examined the associations between blood $\mathrm{Pb}$ levels, follicle-stimulating hormone $(\mathrm{FSH})$, and luteinizing hormones (LH). Serum FSH concentrations statistically significantly increased as blood $\mathrm{Pb}$ levels increased in women who were postmenopausal, both ovaries removed, and premenopausal $(\beta=22.2,32.6$, and 8.3 , respectively). Chang et al. [21] indicated that women with blood $\mathrm{Pb}$ levels higher than $25 \mu \mathrm{g} / \mathrm{L}$ had a 3-fold increased risk of infertility compared with women whose blood $\mathrm{Pb}$ levels were less than $25 \mu \mathrm{g} / \mathrm{L}$.

Although the mechanisms pertaining to the adverse reproductive effects caused by toxic metals have not been fully defined, toxicological studies have provided some insights. Yet, evidence of certain heavy metals contributing to adverse effects on fertility remains incomplete, and knowledge remains fairly limited. Both exogenous exposure and endogenous pathological disorders have been associated with infertility; however, a considerable proportion of infertility cases remain unexplained.

Few studies have directly examined the blood levels of toxic metals in infertile and pregnant women and their relationship to demographic and lifestyle risk factors or hormones. The objective of this study was to examine the blood $\mathrm{Pb}, \mathrm{Cd}$, and As levels in infertile and pregnant women. The relationship among blood $\mathrm{Pb}, \mathrm{Cd}$, and As levels and reproductive hormone of infertile women was evaluated. We evaluated the association between blood metal levels and relevant variables in infertile women. These variables were assessed using structured questionnaires to collect retrospective data, including relevant demographic, physical, environmental, behavioral, and lifestyle factors. The findings of this study could elucidate the distribution and differences in blood $\mathrm{Pb}, \mathrm{Cd}$, and As levels in infertile and pregnant women. Moreover, the results elucidate the association between blood metal levels and the study variables in infertile women.

\section{Methods \\ Study participant recruitment}

This cross-sectional study investigated women aged 18-45 years. Three hundred and sixty-seven patients treated at the Department of Obstetrics and Gynecology of Taiwan Adventist Hospital between August 2008 and March 2010 were enrolled in this study. Women who routinely took medication or dietary supplements were excluded. We categorized the women as infertile or pregnant according to their reproductive outcomes (Fig. 1).

\section{Infertile women}

The infertile group comprised women of childbearing age who encountered difficulty conceiving after 1 year of normal sexual activity with the intention to become pregnant $[22,23]$. The first exclusion criterion was infertile women with a previous diagnosis of polycystic ovary syndrome (PCOS). Because PCOS is a leading cause of female subfertility [24] and a prevalent endocrine disorder in women, it might interfere with the observation of blood metal and hormone concentrations. The PCOS cases were identified by gynecologists and obstetricians who conducted regular hormone examinations and vaginal ultrasound scans. PCOS diagnosis was made according to the presence of chronic anovulation associated with clinical or biochemical hyperandrogenism. Patients with prediagnosed diabetes mellitus, nonclassical adrenal 21-hydroxylase deficiency, hyperprolactinemia, or androgen-secreting tumors were excluded from the current study [25-27]. Participants diagnosed with congenital adrenal hyperplasia or Cushing syndrome were also excluded. The initial number of infertile women in our study totaled 389. After the exclusion of 79 women with a previous diagnosis of PCOS, our study included a total of 310 infertile women participants. 


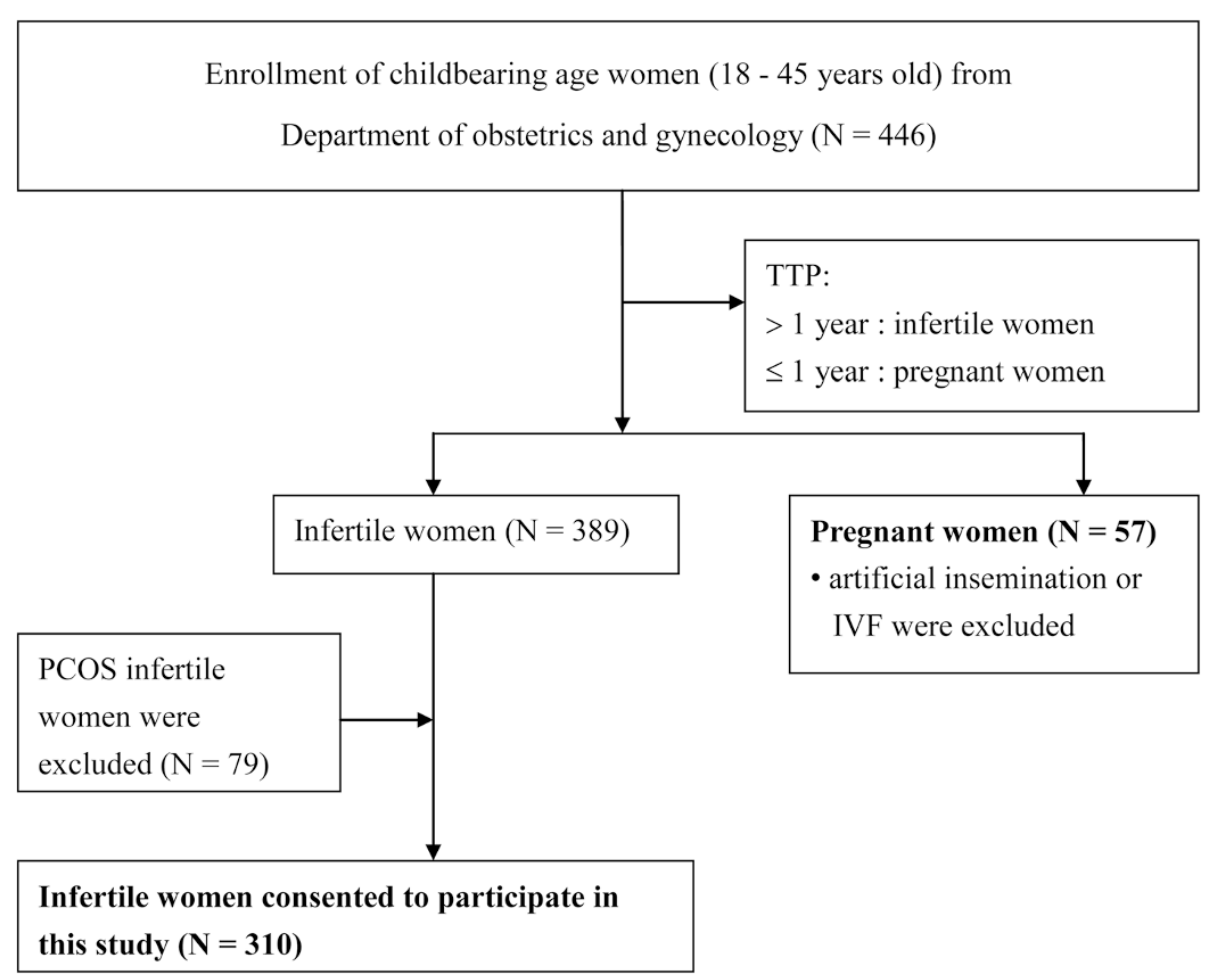

Fig. 1 Flow chart of recruiting eligible childbearing age women of this study. TTP: Time to pregnancy. IVF: In vitro fertilization

\section{Pregnant women}

The pregnant group comprised women of child-bearing age who became pregnant within 1 year of regular unprotected intercourse. Eligible women underwent an ultrasound examination and fetal heartbeat assessment to confirm the pregnancy. For collecting blood samples to represent the exposure of participants before pregnancy, we recruited pregnant women who were in the first 8-10 weeks of gestation. Sixty-five eligible women were initially recruited. Women who received artificial insemination or in vitro fertilization (IVF), and women who ultimately did not have a successful delivery were excluded. After excluding five women who had IVF, two women whose pregnancy lasted for more than 10 weeks, and one woman who ultimately did not have a successful delivery, a total of 57 pregnant women were included in this group.

\section{Data collection}

All the participants provided written informed consent before this study began. This study was approved by the Institutional Review Board of Taipei Medical University (approval number: P950045) and the Taiwan Adventist Hospital Investigational Review Board (TAIRB number: 989801A). We collected self-reported participant sociodemographic and lifestyle data for the year prior to study enrollment. Therefore, the lifestyle data, including alcohol consumption and Chinese herbal medicine use, presented the condition of the pregnant participants before pregnancy was confirmed. A trained interviewer administered a standard face-to-face questionnaire to each participant to obtain the potential factors that might reveal their body burden of metals, including sociodemographic information, lifestyle characteristics, anthropometry, and menstruation history [28-30]. Education level was dichotomized as equal to or below senior high school, and university or above. Occupational exposure was confirmed by asking participants whether they had worked in a job that exposed them to toxic metals for at least one month in the year before this study. Average family income was dichotomized as US $\$ 3,500$ or less per month and greater than US\$3,500 per month. Regular menstruation was defined as a 24-35 day a menstruation cycle, and irregular menstruation was defined as menstrual cycle of less than eight times per year or more than 35 days per cycle. Alcohol consumption was defined as drinking in excess of one standard drink (equivalent to $14 \mathrm{~g}$ [0.6 ounces] of pure alcohol) per day, based on the recommendation of Dietary Guidelines for Americans (2010) [31]. Participants were classified as smokers if they were current smokers who had smoked more than 100 cigarettes in their entire lifetime [32]. Nonsmokers were defined as women who had never smoked or who had quit smoking for over 1 year before the study [33, 34]. In our 
study questionnaires, the Chinese herbal medicine items considered were Angelicae sinensis radix, Lycii fructus, Zizyphi fructu, and Si-Wu-Tang; these were selected because they are most frequent herbal medicines used by women of childbearing age for achieving optimal health in Chinese society [35].

\section{Blood sample collection and analysis}

For the pregnant women, blood samples were collected within the first 8-10 weeks of gestation. For the infertile women, an overnight fasting blood sample was obtained within the first 3 days of the menstrual cycle for those who ovulated spontaneously, or was obtained randomly from those who had amenorrhea longer than 3 months without hormone-induced withdrawal bleeding.

\section{Determination of metal concentrations}

Blood samples were collected from each participant in $10 \mathrm{~mL}$ ethylenediaminetetraacetic acid tubes. Approximately $1 \mathrm{~mL}$ of each blood sample was microwave digested (CEM, Model MDS-2000) with $3 \mathrm{~mL}$ of $65 \%$ nitric acid (Suprapur, Merck). Subsequently, we washed the residuals in microwave tubes with $2 \%$ nitric acid and then filtered the digested fluids with $0.45 \mu \mathrm{m}$ filtered tap water. The total filtered solutions were stored in $15 \mathrm{~mL}$ centrifuge tubes. The levels of $\mathrm{Pb}, \mathrm{Cd}$, and $\mathrm{As}$ were determined using inductively coupled plasma mass spectrometry (ICP-MS; Thermo X-series II). The ICPMS detection limits for $\mathrm{Pb}, \mathrm{Cd}$, and As were $0.23,0.08$, and $0.12 \mathrm{ppb}$, respectively. The method detection limits for $\mathrm{Pb}, \mathrm{Cd}$, and $\mathrm{As}$ were $0.74,0.26$, and $0.39 \mathrm{ppb}$, respectively.

Trace Elements Whole Blood Level 3 (Seronorm $^{\mathrm{Tx}}$; SERO, Billingstad, Norway) was used as the reference material for the standard material test to ensure the precision and accuracy of the blood metal analysis. The precision levels of $\mathrm{Pb}, \mathrm{Cd}$, and As were 97.6, 95.7, and $94.2 \%$, respectively, and the accuracy values were 100.0, 99.9 , and $99.9 \%$, respectively.

\section{Reproductive hormone concentrations in infertile women}

Reproductive hormones were measured in whole blood samples that were collected in vacutainers without an anticoagulant, and then centrifuged at 3,000 rpm for 10 min within $2 \mathrm{~h}$ after the collection. The samples were then stored at $-20{ }^{\circ} \mathrm{C}$ until analysis. FSH and LH levels in the test samples were determined using radioimmunoassay kits (Diagnostic Products Corporation, USA and Diagnostic System Inc., USA, respectively) in an accredited laboratory at Taiwan Adventist Hospital (certified by the Department of Health, Taiwan) [36]. The inter-assay coefficients of variation for LH and FSH were 15.1 and $18.3 \%$, respectively; the intra-assay coefficients of variation for LH and FSH were 6.5 and $8.9 \%$, respectively.
The hormone assay results for the LH and FSH levels are presented as $\mathrm{mIU} / \mathrm{mL}$.

\section{Statistical analysis}

The distributions of continuous variables are expressed as mean \pm standard deviation (SD). Student's, Mann-Whitney U, and Kruskal-Wallis tests were conducted to assess the differences in continuous variables between the infertile and pregnant women. A chi-square test was performed to determine the independence of two categorical variables. The Spearman correlation coefficient ( $\rho$ value) was used to assess the correlation between blood metal concentrations, hormone levels, and potential variables in the infertile women group. Multiple linear regression was conducted to assess the log transformed blood $\mathrm{Pb}, \mathrm{Cd}$, and As levels, and relevant variables in the group. The correlation between blood $\mathrm{Pb}$ levels and Chinese herbal medicine use in infertile women was determined using the Spearman correlation test. Adjusted odds ratios (aORs) between relevant variables and elevated blood $\mathrm{Pb}$ levels, and their corresponding $95 \%$ confidence intervals (CIs), of infertile women were computed through a logistic regression analysis of blood $\mathrm{Pb}$ levels. These blood $\mathrm{Pb}$ levels were categorized as higher than the 75th percentile (Q3) or lower than the 25th percentile (Q1), with blood Pb levels in Q1 as the referent. All statistical analyses were performed using SPSS Version 18.0 for Windows (SPSS Inc., Chicago, IL, USA). A 2-tailed test $\mathrm{p}$ value of $<0.05$ was considered statistically significant.

\section{Results}

Table 1 shows a summary of sociodemographic and lifestyle characteristics and the blood metal levels for each research participant. The participants were aged 18-45 years, and the infertile and pregnant women groups exhibited similar mean ages and body mass indices. A significant difference was observed in the categorized frequencies of Chinese herbal medicine use between the groups $(p<0.01)$. In particular, an obvious difference was noted in infertile women taking Chinese herbal medicine 1-6 times per week compared with pregnant women (30.9 \% versus $10.5 \%$ ). A higher percentage of the infertile women consumed alcohol as usual than did the pregnant women $(27.7 \%$ versus $13.2 \%, p<0.05)$. Furthermore, the pregnant women participated in regular physical activity (more than three times per week) more frequently than did the infertile women $(32.7 \%$ versus $15.6 \%, p<0.05)$. The blood $\mathrm{Pb}$ and As levels were also significantly higher in the infertile women than in the pregnant women $(p<$ 0.01 ). Figure 2 depicts box and whisker plots showing the blood $\mathrm{Pb}, \mathrm{Cd}$, and As levels in infertile and 
Table 1 Sociodemographic and lifestyle characteristics of participants

\begin{tabular}{|c|c|c|c|}
\hline \multirow[t]{2}{*}{ Variable } & \multirow{2}{*}{$\begin{array}{l}\text { Infertile women } \\
(N=310) \\
\text { Number (\%) }\end{array}$} & $\begin{array}{l}\text { Pregnant women } \\
(N=57)\end{array}$ & \multirow[t]{2}{*}{$p$ value } \\
\hline & & Number (\%) & \\
\hline $\mathrm{Age}^{\mathrm{a}}$ (years old) & $35.2 \pm 3.9$ & $34.8 \pm 4.1$ & 0.45 \\
\hline \multicolumn{4}{|l|}{ Education level } \\
\hline$\leq$ Senior high school & $32(10.3 \%)$ & $4(7.1 \%)$ & 0.61 \\
\hline University or above & $276(89.7 \%)$ & $52(92.9 \%)$ & \\
\hline \multicolumn{2}{|l|}{ Occupational exposure ${ }^{b}$} & & 0.81 \\
\hline No & $287(92.7 \%)$ & $54(94.6 \%)$ & \\
\hline Yes & $23(7.3 \%)$ & $3(5.4 \%)$ & \\
\hline \multicolumn{2}{|l|}{ Family income (\$/month) } & & 0.41 \\
\hline$\leq 3500$ & $155(50.8 \%)$ & $25(43.9 \%)$ & \\
\hline$>3500$ & $150(49.2 \%)$ & $32(56.1 \%)$ & \\
\hline $\mathrm{BM} l^{\mathrm{a}}\left(\mathrm{kg} / \mathrm{m}^{2}\right)$ & $21.5 \pm 3.5$ & $21.2 \pm 2.5$ & 0.62 \\
\hline \multicolumn{2}{|l|}{ Menstruation $^{c}$} & & 0.68 \\
\hline Regular & $234(78.3 \%)$ & $37(82.2 \%)$ & \\
\hline Irregular & $65(21.7 \%)$ & $8(17.8 \%)$ & \\
\hline \multicolumn{2}{|l|}{ Fish consumption } & & 0.77 \\
\hline Never & $13(4.2 \%)$ & $3(5.3 \%)$ & \\
\hline$\leq$ meal/week & $123(39.9 \%)$ & $20(35.1 \%)$ & \\
\hline$>1$ meal/week & $172(55.8 \%)$ & $34(59.6 \%)$ & \\
\hline \multicolumn{2}{|c|}{ Chinese herbal medicine use } & & $0.00^{* *}$ \\
\hline No (<1/month) & $140(46.1 \%)$ & $39(68.4 \%)$ & \\
\hline 1-3 times/month & $71(23.0 \%)$ & $12(21.1 \%)$ & \\
\hline 1-6 times/week & $94(30.9 \%)$ & $6(10.5 \%)$ & \\
\hline \multicolumn{2}{|l|}{ Alcohol consumption } & & $0.04^{*}$ \\
\hline No & $219(72.3 \%)$ & $46(88.5)$ & \\
\hline$Y_{e s}{ }^{d}$ & $84(27.7 \%)$ & $6(11.5 \%)$ & \\
\hline \multicolumn{2}{|l|}{ Smoking ${ }^{e}$} & & 0.54 \\
\hline No & 287(95.0 \%) & $51(98.1 \%)$ & \\
\hline Yes & $15(5.0 \%)$ & $1(1.9 \%)$ & \\
\hline \multicolumn{2}{|l|}{ Physical activity } & & $0.00^{* *}$ \\
\hline No & $90(29.3 \%)$ & $5(10.2 \%)$ & \\
\hline 1-2/week & $193(62.9 \%)$ & $28(57.1 \%)$ & \\
\hline$\geq 3 /$ week & $24(7.8 \%)$ & $16(32.7 \%)$ & \\
\hline \multicolumn{4}{|l|}{ Blood metals ${ }^{a}$} \\
\hline $\mathrm{Pb}(\mu \mathrm{g} / \mathrm{L})$ & $17.24 \pm 8.08$ & $12.56 \pm 4.59$ & $0.00^{* *}$ \\
\hline $\mathrm{Cd}(\mu \mathrm{g} / \mathrm{L})$ & $1.48 \pm 0.89$ & $1.37 \pm 0.31$ & 0.79 \\
\hline As $(\mu \mathrm{g} / \mathrm{L})$ & $13.90 \pm 5.54$ & $11.58 \pm 2.92$ & $0.00^{* *}$ \\
\hline \multicolumn{4}{|c|}{ 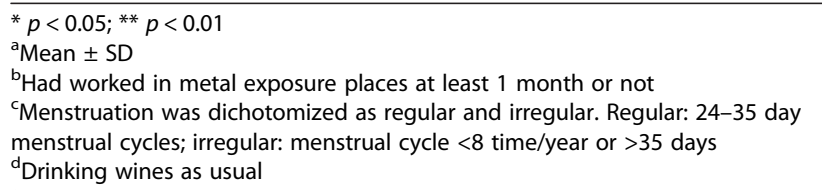 } \\
\hline
\end{tabular}

pregnant women. The median concentrations of $\mathrm{Pb}$, $\mathrm{Cd}$, and As were 15.7, 1.3, and $13.8 \mu \mathrm{g} / \mathrm{L}$ for the infertile women, and 11.6, 1.3, and $10.9 \mu \mathrm{g} / \mathrm{L}$ for the pregnant women, respectively. The blood $\mathrm{Pb}$ and As levels were significantly higher among the infertile women than among the pregnant women $(p<0.01)$.

In order to interpret the associations on blood $\mathrm{Pb}$ levels between infertility and Chinese herbal medicine use. We analyzed the blood $\mathrm{Pb}$ levels for infertile and pregnant group by Mann-Whitney $U$ test. We dichotomized the variable of Chinese herbal medicine use to "no" and "yes" by the frequency of 1 time/month (Table 2). The results showed that the blood $\mathrm{Pb}$ levels of infertile women [14.83 (11.34-18.44) $\mu \mathrm{g} / \mathrm{L}]$ were significant greater than that of pregnant women $[11.49(7.78-14.91) \mu \mathrm{g} / \mathrm{L}]$ among no Chinese herbal medicine use $(p<0.01)$. Chinese herbal medicine use may raise the blood $\mathrm{Pb}$ levels both in infertile $[16.61(11.94-22.10) \mu \mathrm{g} / \mathrm{L}]$ and pregnant women [14.00 (9.96-17.56) $\mu \mathrm{g} / \mathrm{L}](p<0.05)$.

Table 3 shows the correlations among the levels of $\mathrm{Pb}$, $\mathrm{Cd}$, As, and the reproductive hormones in the blood. The blood Cd levels were correlated negatively with blood As levels $(\rho=-0.12, p<0.05)$. A significant but weak positive correlation existed between the blood $\mathrm{Cd}$ and Pb levels $(\rho=0.22, p<0.01)$, and LH levels were correlated positively with the FSH levels $(\rho=0.14, p<0.05)$.

Multiple linear regression models were used to evaluate the influence of study variables (age, educational level, occupational exposure, family income, BMI, menstruation, fish consumption, Chinese herbal medicine use, alcohol consumption, smoking status, and physical activity) on the blood metal levels in the infertile women (Table 4). Chinese herbal medicine use showed a significant correlation to blood $\mathrm{Pb}$ levels $(\beta=0.04, p=0.02)$, menstruation exhibited a significant correlation to blood $\mathrm{Cd}$ levels $(\beta=-0.06, p=$ $0.05)$, and family income revealed a significant correlation to blood As levels $(\beta=-0.05, p=0.04)$.

We further analyzed relevant variables and the blood $\mathrm{Pb}$ levels in the infertile women by using a logistic regression model adjusted for potentially relevant predictors. We initially tried to assess the dose-response effect for quartile of blood $\mathrm{Pb}$. Compared to the referent blood $\mathrm{Pb}$ levels lower than Q1, the dose-response effect could not be observed (data not shown). Nevertheless, compared with the referent blood $\mathrm{Pb}$ levels lower than Q1, elevated blood $\mathrm{Pb}$ levels (higher than Q3) were found in categorized group of Chinese herbal medicines use 1-6 times per week $(\mathrm{aOR}=2.82,95 \% \mathrm{CI}$ 0.98-8.09). The high $\mathrm{Pb}$ burden might result from consuming Chinese herbal medicines, even though marginal significance $(p=$ $0.05)$. Exercising 1-2 times per week was also marginally significant $(p=0.05)$; therefore, exercise might reduce $\mathrm{Pb}$ accumulation in infertile women $(\mathrm{aOR}=0.37,95 \% \mathrm{CI}$ 


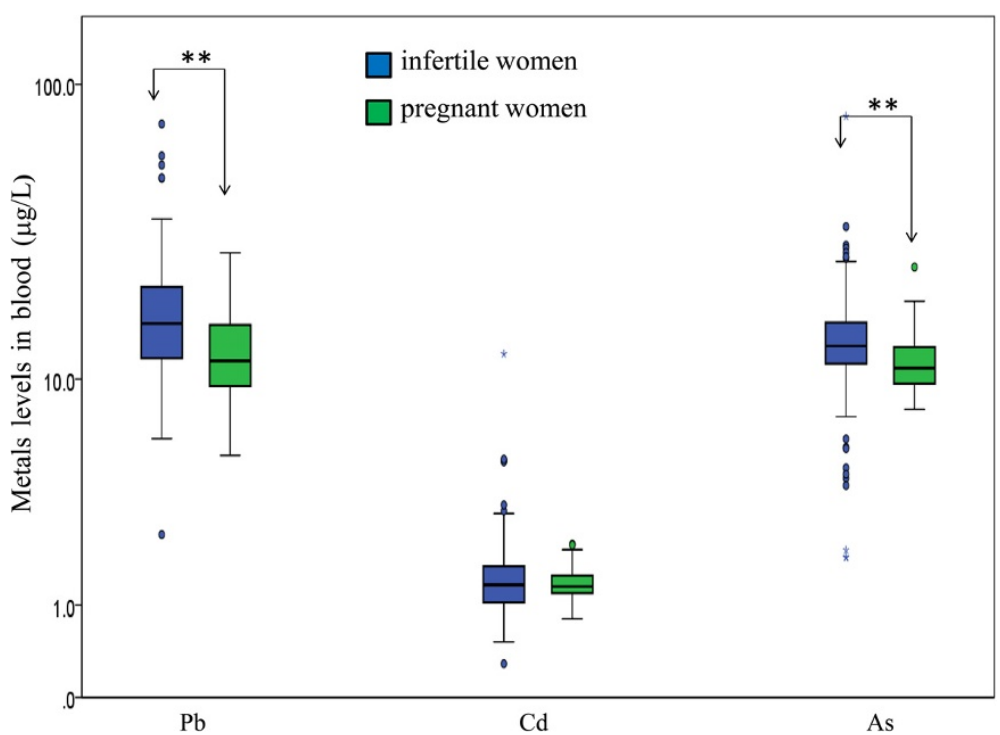

Fig. 2 Box and whisker plots display the distribution of the blood Pb, Cd, As levels in participants. Infertile women $(N=310)$ and pregnant women $(N=57) .{ }^{* *} p<0.01$

0.14-1.00). Finally, we presented the results compared with the referent blood $\mathrm{Pb}$ levels lower than Q1, and blood $\mathrm{Pb}$ levels higher than Q3 in the Table 5.

As shown in Fig. 3, blood Pb levels increased with the frequency of Chinese herbal medicine consumption among the infertile women. Chinese herbal medicine consumption was classified into three frequencies: none, 1-3 times per month, and 1-6 times per week. Blood $\mathrm{Pb}$ concentration was observed to increase with frequency of Chinese herbal medicine consumption. The geometric mean blood $\mathrm{Pb}$ levels in the none, 1-3 times per month, and 1-6 times per week groups were 14.46, 15.67, and $16.95 \mu \mathrm{g} / \mathrm{L}$, respectively (Fig. 3, $p<0.01$ ).

\section{Discussion}

This is one of the few studies assessing the blood levels of $\mathrm{Pb}, \mathrm{Cd}$, and $\mathrm{As}$, along with other relevant variables, by categorizing women of childbearing age as infertile or pregnant. Our results indicate that blood $\mathrm{Pb}$ and As, but not $\mathrm{Cd}$, levels were significantly higher in the infertile women compared with the pregnant women. In addition to the high blood metal levels, we observed some lifestyle differences in the infertile women, including greater consumption of alcohol and Chinese herbal medicine and a lack of physical activity.

Bloom et al. [3] reported that the respective blood $\mathrm{Pb}$ levels in pregnant and nonpregnant women were $15.44 \pm 1.23$ and $15.54 \pm 1.57 \mu \mathrm{g} / \mathrm{L}$, respectively; this is comparable to our findings. According to the nationwide Environmental Health Monitoring System in the Czech Republic, the median blood Pb levels of 18- to 58 -year-old women was $14 \mu \mathrm{g} / \mathrm{L}$ in 2009 [37], which is also comparable to our results. Furthermore, Chang et al. [21] investigated the relationship between $\mathrm{Pb}$ exposure and the risk of infertility in women between 2000 and 2001 in Taiwan, reporting mean blood $\mathrm{Pb}$ levels of 35.5 and $27.8 \mu \mathrm{g} / \mathrm{L}$ in infertile women and pregnant women, respectively. The blood $\mathrm{Pb}$ levels reported in that study are significantly higher than those observed in our study, possibly because lead fuels were prohibited in Taiwan in 2000.

Bloom et al. [3] studied 18- to 34-year-old women and reported blood Cd levels of $1.67 \pm 2.82$ and $1.52 \pm$ $0.95 \mu \mathrm{g} / \mathrm{L}$ in pregnant and nonpregnant women, respectively, the results were similar to our study.

Table 2 Blood Pb levels distribution among women with infertile or pregnancy and dichotomized by Chinese herbal medicine use

\begin{tabular}{|c|c|c|c|c|c|}
\hline \multirow[t]{2}{*}{ Chinese herbal medicine use } & \multicolumn{2}{|c|}{ Infertile women } & \multicolumn{2}{|c|}{ Pregnant women } & \multirow[t]{2}{*}{$p$ valu } \\
\hline & Median & Q1 - Q3 & Median & Q1 - Q3 & \\
\hline \multirow[t]{2}{*}{ No (<1 time/month) } & 14.83 & $11.34-18.44$ & 11.49 & $7.78-14.91$ & $<0.01$ \\
\hline & $(n=136)$ & & $(n=39)$ & & \\
\hline \multirow[t]{2}{*}{ Yes ( $\geq 1$ time/month) } & 16.61 & $11.94-22.10$ & 14.00 & $9.96-17.56$ & $<0.05$ \\
\hline & $(n=163)$ & & $(n=18)$ & & \\
\hline
\end{tabular}


Table 3 Correlations between metals levels and reproductive hormones in blood from infertile women $(N=310)$

\begin{tabular}{lllll}
\hline Variable & $\mathrm{Pb}$ & $\mathrm{Cd}$ & $\mathrm{As}$ & $\mathrm{FSH}$ \\
\hline $\mathrm{Cd}$ & $0.22^{* *}$ & & & \\
As & -0.03 & $-0.12^{*}$ & & \\
$\mathrm{FSH}$ & 0.07 & -0.01 & 0.06 & \\
$\mathrm{LH}$ & -0.08 & 0.03 & 0.00 & $0.14^{*}$ \\
\hline${ }^{*} p<0.05 ;{ }^{* *} p<0.01$ & & &
\end{tabular}

Recent data from Ikeda et al. [38] reported that the geometric mean of $\mathrm{Cd}$ concentrations in the blood of women in nonpolluted areas of Japan was $1.23 \mu \mathrm{g} / \mathrm{L}$. Additionally, a 2008-2010 national surveillance study in South Korea revealed that the geometric mean $\mathrm{Cd}$ blood concentrations was $1.20 \mu \mathrm{g} / \mathrm{L}$ in 40 - to 49 -yearold women [39]. These findings are also comparable to our results. Among nonoccupationally exposed people, tobacco is the leading source of exposure to Cd [40, 41]. However, in this study, a nonsignificant difference in blood $\mathrm{Cd}$ levels was observed between the infertile and pregnant women (Table 1), potentially because of the low percentage of participants who were smokers $(5.0 \%$ of infertile women and $1.9 \%$ of pregnant women). Compared with the results of our study and previous findings $[3,42,43]$, a variety range of blood As levels in women were observed.

Many infertile women use Chinese herbal medicine to assist them in conceiving, but doing so may expose them to $\mathrm{Pb}, \mathrm{Cd}$, and As. According to a report from the Division of Research and Analysis of the Taiwan Food and Drug Administration [44], these toxic metals can be found in ten common raw Chinese herbs. The 80th percentile of each heavy metal in these unprocessed herbs is within $0.19-6.53 \mathrm{mg} / \mathrm{L}$ for $\mathrm{Pb}, 0.04-1.68 \mathrm{mg} / \mathrm{L}$ for $\mathrm{Cd}$, and $0.09-2.34 \mathrm{mg} / \mathrm{L}$ for As. Toxic metals such as $\mathrm{Pb}$, $\mathrm{Cd}$, and As, which have been detected in commercially available Chinese herbal medicines, may pose a health risk to these women $[35,45,46]$. Si-Wu-Tang is also used to treat irregular menses, period pain, overactive fetuses, anemia, and other blood stasis conditions. Si-Wu-Tang has the highest lead concentration among all Chinese herbal products, with a level approximately 8.8-16.6 times higher than other herbs [35]. Wu et al. [47] urged greater attention be paid to high $\mathrm{Pb}$ exposure from Chinese herbal medicine consumption. The infertile women in the $\mathrm{Wu}$ et al. study were more likely to consume Chinese herbal medicine than were the pregnant women. These findings were consistent with our study results of Table 2 that Chinese herbal medicine use might be one of important source of $\mathrm{Pb}$ exposure in childbearing age women, and the elevated blood $\mathrm{Pb}$ level might be the risk factor that causes women infertility. The correlation between Chinese herbal medicine use and blood As levels was borderline significant in infertile women (Table $4 ; p=0.06$ ), which might indicate a certain contribution to greater blood As levels from Chinese herbal medicine use. Among the infertile women, blood As levels were significantly higher among

Table 4 Multiple linear regression in metals levels and relevant variables of infertile women $(N=310)$

\begin{tabular}{|c|c|c|c|c|c|c|}
\hline \multirow[t]{2}{*}{ Variables } & \multicolumn{2}{|c|}{ Blood Pb } & \multicolumn{2}{|c|}{ Blood Cd } & \multicolumn{2}{|c|}{ Blood As } \\
\hline & $\bar{\beta}$ & $p$ value & $\bar{\beta}$ & $p$ value & $\beta$ & $\mathrm{p}$ value \\
\hline Age (years old) & 0.00 & 0.28 & 0.01 & 0.14 & 0.00 & 0.65 \\
\hline Education level $^{a}$ & -0.02 & 0.69 & 0.06 & 0.21 & -0.03 & 0.53 \\
\hline Occupational exposure ${ }^{b}$ & 0.01 & 0.79 & -0.01 & 0.85 & 0.02 & 0.57 \\
\hline Family income $e^{c}$ & 0.02 & 0.45 & 0.01 & 0.85 & $-0.05^{*}$ & $0.04^{*}$ \\
\hline $\mathrm{BMI}\left(\mathrm{kg} / \mathrm{m}^{2}\right)$ & 0.00 & 0.96 & -0.01 & 0.24 & -0.00 & 0.74 \\
\hline Menstruation $^{d}$ & -0.03 & 0.31 & -0.06 & $0.05^{*}$ & -0.03 & 0.26 \\
\hline Fish consumption ${ }^{\mathrm{e}}$ & 0.01 & 0.63 & -0.02 & 0.31 & 0.03 & 0.09 \\
\hline Chinese herbal medicine use ${ }^{f}$ & 0.04 & $0.02^{*}$ & -0.01 & 0.49 & 0.02 & 0.06 \\
\hline Alcohol consumption ${ }^{9}$ & 0.00 & 0.95 & 0.03 & 0.29 & -0.02 & 0.50 \\
\hline Smoking ${ }^{\text {h }}$ & 0.11 & 0.06 & -0.06 & 0.29 & 0.03 & 0.51 \\
\hline Physical activity ${ }^{i}$ & -0.03 & 0.24 & -0.03 & 0.12 & -0.00 & 0.91 \\
\hline
\end{tabular}

* $p<0.05$

${ }^{a}$ Education levels were dichotomized as $\leq$ Senior high school and University or above

${ }^{\mathrm{b}} \mathrm{Had}$ worked in metal exposure places at least one month or not

${ }^{c}$ Family income was dichotomized at US\$3,500 per month

${ }^{\mathrm{d}}$ Menstruation was dichotomized as regular and irregular. Regular: 24-35 day menstrual cycles; irregular: menstrual cycle $<8$ time/year or $>35$ days

${ }^{e}$ Fish consumption was categorized in 3 frequencies as never, $\leq 1 \mathrm{meal} /$ week, and $>1 \mathrm{meal} / \mathrm{week}$

${ }^{\mathrm{f}}$ Chinese herbal medicine use was categorized in 3 frequencies as no $(<1 /$ month), $1-3$ times/month, and $1-6$ times/week

${ }^{9}$ Alcohol consumption was dichotomized as yes and no. Yes defined as drinking wines as usual

${ }^{\mathrm{h}}$ Smoking was dichotomized as yes and no. Yes: current smokers; No: never-smokers and ex-smokers

'Physical activity was categorized in 3 frequencies as no, 1-2/week, and $\geq 3 /$ week 
Table 5 Adjusted ${ }^{\mathrm{a}}$ logistic regression analyses in relevant variables and blood $\mathrm{Pb}$ levels ${ }^{\mathrm{b}}$ of infertile women

\begin{tabular}{|c|c|c|c|}
\hline Variables & $\mathrm{aOR}$ & $95 \% \mathrm{Cl}$ & $p$ value \\
\hline Age (years old) & 1.07 & $0.96-1.19$ & 0.20 \\
\hline \multicolumn{4}{|c|}{ Occupational exposure ${ }^{c}$} \\
\hline No & 1 & & \\
\hline Yes & 0.83 & $0.15-4.51$ & 0.83 \\
\hline \multicolumn{4}{|c|}{ Family income (\$/month) } \\
\hline$\leq 3500$ & 1 & & \\
\hline$>3500$ & 1.17 & $0.48-2.82$ & 0.73 \\
\hline \multicolumn{4}{|l|}{ Menstruation $^{d}$} \\
\hline Regular & 1 & & \\
\hline Irregular & 1.43 & $0.49-4.14$ & 0.51 \\
\hline \multicolumn{4}{|c|}{ Chinese herbal medicine use } \\
\hline No (<1/month) & 1 & & \\
\hline 1-3 times/month & 0.90 & $0.32-2.52$ & 0.84 \\
\hline 1-6 times/week & 2.82 & $0.98-8.09$ & 0.05 \\
\hline \multicolumn{4}{|l|}{ Alcohol consumption ${ }^{\mathrm{e}}$} \\
\hline No & 1 & & \\
\hline Yes & 0.90 & $0.36-2.27$ & 0.83 \\
\hline \multicolumn{4}{|l|}{ Physical activity } \\
\hline No & 1 & & \\
\hline 1-2/week & 0.37 & $0.14-1.00$ & 0.05 \\
\hline$\geq 3 /$ week & 0.38 & $0.11-1.29$ & 0.12 \\
\hline
\end{tabular}

${ }^{a}$ Adjusted on age, occupational exposure, family income, menstruation, Chinese herbal medicine use, alcohol consumption, physical activity ${ }^{\mathrm{b}}$ Blood $\mathrm{Pb}$ levels in the regression was by evaluated blood $\mathrm{Pb}$ levels $\geq$ Q3(75th) $(21.00 \mu \mathrm{g} / \mathrm{L})$ compared to the referent; the blood Pb levels $\leq \mathrm{Q} 1$ (25th) $(11.83 \mu \mathrm{g} / \mathrm{L})$ is as the referent

${ }^{\mathrm{C}} \mathrm{Had}$ worked in metal exposure places at least one month or not

${ }^{\mathrm{d}}$ Menstruation was dichotomized as regular and irregular. Regular: 24-35 day

menstrual cycles; irregular: menstrual cycle $<8$ time/year or $>35$ days

${ }^{\mathrm{e}}$ Alcohol consumption was dichotomized as yes and no. Yes defined as drinking wines as usual

those in the lower median family income group. This result was similar to those of other studies that reported a significant negative correlation between income and As exposure $[48,49]$.

Anderson et al. [50] suggested that maintaining a healthy lifestyle could assist women in conceiving, and that, to aid in conception, infertile couples should adopt a healthy lifestyle that includes regular physical activity, not smoking, and not consuming alcohol. According to previous studies, the perspiration caused by increased physical activity can increase heavy-metal excretion [51-53], which may reduce blood $\mathrm{Pb}, \mathrm{Cd}$, and As levels and enhance fecundity. As shown in Table 1, the infertile women habitually consumed alcohol, markedly higher $(27.7 \%)$ than that of pregnant women $(11.5 \%)$. Alcohol can have direct adverse effects on the maturation of the ovum [54, 55], ovulation, early blastocyst development, and implantation [56]. Several studies have observed an alcoholinduced increase in estrogen levels in animals and healthy women $[57,58]$, which may reduce FSH secretion, suppress folliculogenesis, and further affect ovulation. These causes may result in adverse fecundity among women of reproductive age. From our study results of Table 1, a greater percentage of alcohol consumption as usual in infertile women than that in pregnant women $(27.7 \%$ versus $11.5 \%, p<0.05)$, and regular physical activity more frequently in the pregnant women than that in infertile women $(32.7 \%$ versus $15.6 \%, p<0.05)$. These results would indicate that women might conceive difficutly due to risk behaviors.

The relationships among toxic metals in the blood have been examined in previous studies. One study found that a significant correlation between the presence of $\mathrm{Pb}$ and $\mathrm{Cd}$ in cattle [59]. A study examining $\mathrm{Pb}$-exposed and nonexposed workers found interactions between blood $\mathrm{Cd}$ and As levels [60]. Significant correlations between blood $\mathrm{Pb}$ and $\mathrm{Cd}$ levels and $\mathrm{Cd}$ and As levels were observed in our study (Table 2), but the causes and mechanisms of these relationships require further study. $\mathrm{Pb}, \mathrm{Cd}$, and $\mathrm{As}$ could be endocrine-disrupting chemicals [61] and could interact with hormones and disrupt endocrine functions that might exert reproductive problems in female [62]. This study yielded no significant correlations between blood metals and hormone levels, which may have occurred because most of the infertile participants lacked occupational or environmental exposure. Although blood $\mathrm{Pb}$ levels were significantly higher in the infertile women than in the pregnant women, the $\mathrm{Pb}$ exposure levels of these populations were below hazard reference values. The median blood $\mathrm{Pb}$ concentration was $15.7 \mu \mathrm{g} / \mathrm{L}$ in the infertile women of our study; yet the U.S. Centers for Disease Control and Prevention recommends that blood $\mathrm{Pb}$ levels not exceed $100 \mu \mathrm{g} / \mathrm{L}$ in women to protect their offspring from toxic effects [63]. This high threshold may be why no obvious effect on reproductive hormones was revealed.

The strength of this study is its assessment of the distribution and differences of the blood metal levels of infertile and pregnant women. However, some bias existed in this study, which is a common limitation of retrospective investigations [64, 65]. Another limitation of this study is that some data regarding sociodemographic and lifestyle factors were self-reported. No dietary record and consumption duration (Chinese herbal medicine) were included in our questionnaire, which may have led to the underestimation of participants' exposure to toxic metals. The potential exposure levels of toxic metals were not collected from the 


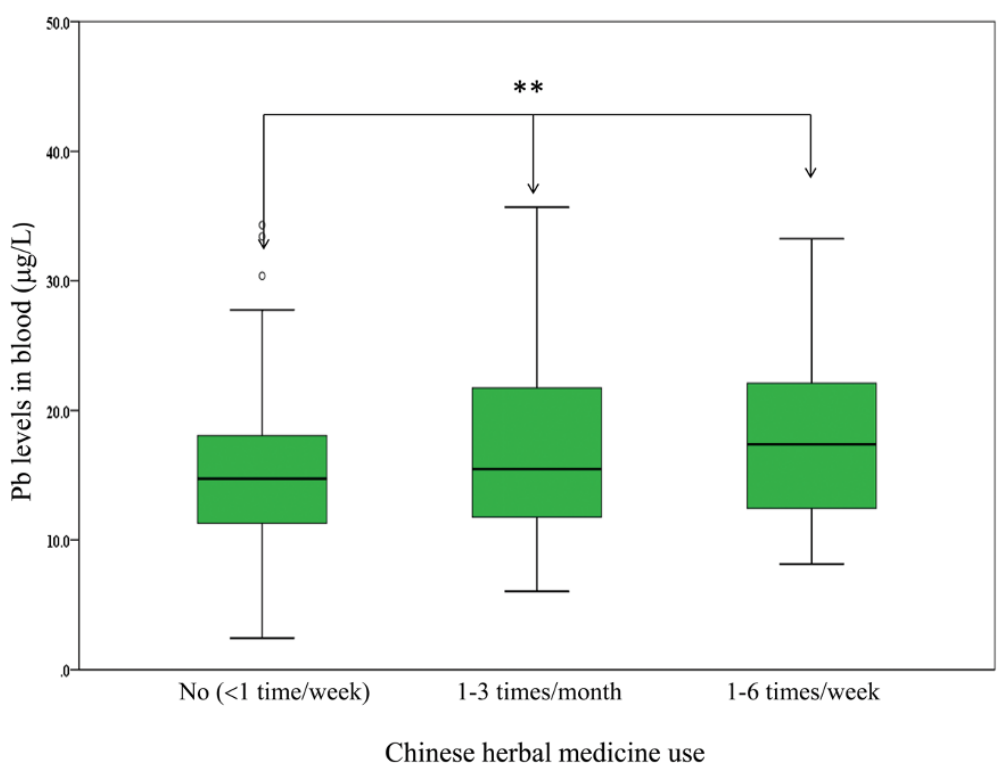

Fig. 3 Blood Pb levels in infertile women by 3 categorized frequencies of Chinese herbal medicine use. ${ }^{* *} p<0.01$

residential areas of our participants; this may also have affected their actual blood metal levels. Certain clinical conditions such as malabsorption may also induce an underestimation of toxic metal concentrations in the blood. Additionally, recruiting healthy pregnant women for this research was difficult because they may have less motivation to participate in medical studies; the number of pregnant women in our study $(N=57)$ was lower than that of the infertile group $(N=310)$. However, we conducted a power of significance test for blood $\mathrm{Pb}$ levels in the pregnant and infertile women, and $p>0.9$. Therefore, even though fewer pregnant women were recruited, the sample was large enough for comparison with the infertile group. Another limitation of this study is that essential metals such as iron, selenium, zinc, magnesium, and calcium, were not measured. These metals may interfere with reproduction in women $[2,66,67]$. More than $80 \%$ of the infertile women in our study came from urban areas. The average family income in Taiwan was estimated to be US\$3,000 per month according to a Taiwan government report [68], and family income was more than US $\$ 3,500$ per month for approximately $50 \%$ of participants in our study. For these reasons, we could assume that the infertile women in this study received adequate nutrition and had a relatively higher socioeconomic status, but no assessment was conducted to determine whether they had any deficiency in essential metals. Moreover, the interaction of essential and toxic metals on hormone levels was not investigated in this study; thus, additional research is necessary to determine whether this interaction affects hormones levels or produces any distinct effects in infertile women.

\section{Conclusion}

Among the variables examined in this study, alcohol consumption, Chinese herbal medicine use, and a lack of exercise was more common among the infertile women than among the pregnant women. Frequently consuming Chinese herbal medicine may have caused elevated blood $\mathrm{Pb}$ levels, and physical activity may have reduced the accumulation of $\mathrm{Pb}$ among the infertile women. The caution of Chinese herbs use is warranted to prevent toxic metals from accumulating in the blood. Regular physical activity may reduce the accumulation of $\mathrm{Pb}$ in the body and improve women's health.

\section{Abbreviations}

Pb: Lead; Cd: Cadmium; As: Arsenic; FSH: Follicle-stimulating hormone; LH: Luteinizing hormone; PCOS: Polycystic ovary syndrome; IVF: In vitro fertilization; SD: Standard deviation; aOR: Adjusted odds ratio; Cl: Confidence interval; Q1: the 25th percentile; Q3: the 75th percentile.

Competing interests

The authors have no competing interests to declare.

\section{Authors' contributions}

HLL was involved in preparing the data, interpreting the results, and writing and critically reviewing the manuscript. HJW was involved in providing clinical expertise, transferring eligible women of childbearing age to our study, and interpreting the results. HYH was involved in providing clinical expertise, interpreting the results, and revising the manuscript. KWL was involved in coordinating the study, analyzing the metals, and preparing the data. LCC was involved in conceiving the study topic, designing the study, providing statistical advice, interpreting the results, and providing critical comments. All authors have read and approved the final article. 


\section{Acknowledgments}

This study received no external funding. The authors express their gratitude to staff at the infertility center, the participating gynecologists from Taiwan Adventist Hospital assisting with data collection, and all participants in this study for their time and effort.

\section{Author details}

'School of Public Health, Taipei Medical University, No. 250, Wuxing St. Taipei City 110, Taiwan. ${ }^{2}$ Infertility Center, Taiwan Adventist Hospital, No. 424, Sec. 2, Bade Rd., Taipei City 105, Taiwan. ${ }^{3}$ Xiamen EMBO Hospital, No. 117-119, Hubin South Road, Xiamen City 361000Fujian Province, China.

Received: 4 March 2015 Accepted: 3 December 2015 Published online: 09 December 2015

\section{References}

1. World Health Organization. Sexual and reproductive health. Available from: [http://www.who.int/reproductivehealth/topics/infertility/perspective/en/ index.html]. Assess Date: 23,10.

2. Mendola P, Messer LC, Rappazzo K. Science linking environmental contaminant exposures with fertility and reproductive health impacts in the adult female. Fertil Steril. 2008:89(2 Suppl):e81-94.

3. Bloom MS, Louis GM, Sundaram R, Kostyniak PJ, Jain J. Associations between blood metals and fecundity among women residing in New York State. Reprod Toxicol (Elmsford, NY). 2011;31(2):158-63.

4. Gardella C. Lead exposure in pregnancy: a review of the literature and argument for routine prenatal screening. Obstet Gynecol Surv. 2001:56(4):231-8.

5. Schoeters $G$, Den Hond E, Zuurbier M, Naginiene R, van den Hazel P, Stilianakis N, et al. Cadmium and children: exposure and health effects. Acta Paediatr Suppl. 2006;95(453):50-4.

6. Holmes $P$, James KA, Levy LS. Is low-level environmental mercury exposure of concern to human health? Sci Total Environ. 2009:408(2):171-82.

7. Ahmad SA, Sayed MH, Barua S, Khan MH, Faruquee MH, Jalil A, et al. Arsenic in drinking water and pregnancy outcomes. Environ Health Perspect. 2001;109(6):629-31.

8. Sengupta P, Banerjee R, Nath S, Das S, Banerjee S. Metals and female reproductive toxicity. Hum Exp Toxicol. 2015;34(7):679-97.

9. Mattison DR. Environmental exposures and development. Curr Opin Pediatr. 2010;22(2):208-18.

10. CDC. Third National Report on Human Exposure to Environmental Chemicals 2005. http://www.jhsph.edu/research/centers-and-institutes/ center-for-excellence-in-environmental-health-tracking/Third_Report.pdf.

11. Gallagher CM, Moonga BS, Kovach JS. Cadmium, follicle-stimulating hormone, and effects on bone in women age 42-60 years, NHANES III. Environ Res. 2010;110(1):105-11.

12. Krieg Jr EF. The relationships between blood lead levels and serum follicle stimulating hormone and luteinizing hormone in the third National Health and Nutrition Examination Survey. Environ Res. 2007;104(3):374-82.

13. Nagata C, Nagao Y, Shibuya C, Kashiki Y, Shimizu H. Urinary cadmium and serum levels of estrogens and androgens in postmenopausal Japanese women. Cancer Epidemiol Biomarkers Prev. 2005;14(3):705-8.

14. Guo Z, Guo H, Xia Y. Effects on endocrine system of female rats exposed to chronic arsenic. J Hyg Res. 2011;40(2):178-9.

15. Zenzes MT, Krishnan S, Krishnan B, Zhang H, Casper RF. Cadmium accumulation in follicular fluid of women in in vitro fertilization-embryo transfer is higher in smokers. Fertil Steril. 1995;64(3):599-603.

16. Paksy K, Gáti I, Náray M, Rajczy K. Lead accumulation in human ovarian follicular fluid, and in vitro effect of lead on progesterone production by cultured human ovarian granulosa cells. J Toxicol Environ Health, Part A. 2001;62(5):359-66

17. Al Saleh I, Coskun S, Mashhour A, Shinwari N, El-Doush I, Billedo G, et al. Exposure to heavy metals (lead, cadmium and mercury) and its effect on the outcome of in-vitro fertilization treatment. Int J Hyg Environ Health. 2008;211(5-6):560-79.

18. Langley S. A Nutrition Screening Form for Female Infertility Patients. Can J Diet Pract Res. 2014;75(4):195-201.

19. Tokar EJ, Benbrahim-Tallaa L, Waalkes MP. Metal ions in human cancer development. Met lons Life Sci. 2011;8:375-401.
20. Randolph JF, Ginsburg KA, Leach RE, Blacker CM, Moghissi KS, Diamond MP, et al. Elevated early follicular gonadotropin levels in women with unexplained infertility do not provide evidence for disordered gonadotropin-releasing hormone secretion as assessed by luteinizing hormone pulse characteristics. Fertil Steril. 2003;80(2):320-7.

21. Chang SH, Cheng BH, Lee SL, Chuang HY, Yang CY, Sung FC, et al. Low blood lead concentration in association with infertility in women. Environ Res. 2006;101(3):380-6.

22. Cooper TG, Noonan E, von Eckardstein S, Auger J, Baker HW, Behre HM, et al. World Health Organization reference values for human semen characteristics. Hum Reprod Update. 2010;16(3):231-45.

23. Gurunath S, Pandian Z, Anderson RA, Bhattacharya S. Defining infertility-a systematic review of prevalence studies. Hum Reprod Update. 2011;17(5):575-88.

24. Azziz R, Woods KS, Reyna R, Key TJ, Knochenhauer ES, Yildiz BO. The prevalence and features of the polycystic ovary syndrome in an unselected population. J Clin Endocrinol Metab. 2004;89(6):2745-9.

25. BCJM F. Revised 2003 consensus on diagnostic criteria and long-term health risks related to polycystic ovary syndrome. Fertil Steril. 2004;81(1):19-25.

26. Legro RS, Kunselman AR, Dodson WC, Dunaif A. Prevalence and predictors of risk for type 2 diabetes mellitus and impaired glucose tolerance in polycystic ovary syndrome: a prospective, controlled study in 254 affected women. J Clin Endocrinol Metab. 1999;84(1):165-9.

27. Ehrmann DA, Barnes RB, Rosenfield RL, Cavaghan MK, Imperial J. Prevalence of impaired glucose tolerance and diabetes in women with polycystic ovary syndrome. Diabetes Care. 1999;22(1):141-6.

28. Ji Ye Shin JMK, Kim Y. The association of heavy metals in blood, fish consumption frequency, and risk of cardiovascular diseases among Korean adults: The Korean National Health and Nutrition Examination Survey (2008-2010). Korean J Nutr. 2012;45(4):347-61.

29. McKelvey W, Gwynn RC, Jeffery N, Kass D, Thorpe LE, Garg RK, et al. A biomonitoring study of lead, cadmium, and mercury in the blood of New York city adults. Environ Health Perspect. 2007;115(10):1435-41.

30. Son JY, Lee J, Paek D, Lee JT. Blood levels of lead, cadmium, and mercury in the Korean population: Results from the Second Korean National Human Exposure and Bio-monitoring Examination. Environ Res. 2009;109(6):738-44.

31. USDA, HHS. Dietary Guidelines for Americans, 2010 Available from: [http:// www.health.gov/dietaryguidelines/]. Assess Date: 05/07/2014.

32. Siegel $M$, Biener $L$. The impact of an antismoking media campaign on progression to established smoking: results of a longitudinal youth study. Am J Public Health. 2000;90(3):380-86.

33. Shurtleff D. Some characteristics related to the incidence of cardiovascular disease and death: Framingham study, 18-year follow-up, Section 30. In: Kannel WB, Gordon T, editors. No. (NIH) 74-599, U.S. Department of Health, Education, and Welfare. Washington, DC: DHEW Publication; 1974.

34. Waldron I. The contribution of smoking to sex differences in mortality. Public Health Rep. 1986;101(2):163-73.

35. Chien LC, Yeh CY, Lee HC, Chao H, Shieh MJ, Han BC. Effect of the mother's consumption of traditional Chinese herbs on estimated infant daily intake of lead from breast milk. Sci Total Environ. 2006;354(2-3):120-26.

36. Liou SH, Yang GY, Wu TN, Ko YC, Lee CC, Ho ST, et al. Assessment of Interlaboratory Performance on the Measurement of Blood Lead Levels in Taiwanese Adults. Ind Health. 1995:33:181-90.

37. Cerna M, Krskova A, Cejchanova M, Spevackova V. Human biomonitoring in the Czech Republic: an overview. Int J Hyg Environ Health. 2012;215(2):109-19.

38. Ikeda M, Ohashi F, Fukui Y, Sakuragi S, Moriguchi J. Cadmium, chromium, lead, manganese and nickel concentrations in blood of women in non-polluted areas in Japan, as determined by inductively coupled plasma-sector field-mass spectrometry. Int Arch Occup Environ Health. 2011;84(2):139-50.

39. Lee BK, Kim Y. Association of blood cadmium with hypertension in the Korean general population: Analysis of the 2008-2010 Korean national health and nutrition examination survey data. Am J Ind Med. 2012;55(11):1-8.

40. Jarup L. Hazards of heavy metal contamination. Br Med Bull. 2003;68:167-82.

41. Satarug S, Moore MR. Adverse health effects of chronic exposure to low-level cadmium in foodstuffs and cigarette smoke. Environ Health Perspect. 2004;112(10):1099-103.

42. Sanders AP, Flood K, Chiang S, Herring AH, Wolf L, Fry RC. Towards prenatal biomonitoring in North Carolina: assessing arsenic, cadmium, mercury, and lead levels in pregnant women. PLoS One. 2012;7(3):e31354 
43. Ahsan H, Chen Y, Parvez F, Argos M, Hussain Al, Momotaj H, et al. Health Effects of Arsenic Longitudinal Study (HEALS): description of a multidisciplinary epidemiologic investigation. J Expo Sci Environ Epidemiol. 2006;16(2):191-205.

44. Chen YH, Lu FL, Liu YC, Shih YC. Survey on Heavy Metals in Raw Materials of Traditional Chinese Medicine (IX). Ann Rept Food Drug Res. 2013;4:228-35.

45. Liu XJ, Liu WJ, Lin AJ, Liu YX. Survey of arsenic concentrations in Chinese herbal medicines (CHMs) and preliminary risk assessment of As in CHMs on human health. Chin J Environ Sci. 2010;31(12):3036-42.

46. Ernst $\mathrm{E}$, Thompson Coon J. Heavy metals in traditional Chinese medicines: a systematic review. Clin Pharmacol Ther. 2001;70(6):497-504.

47. Wu T-N, Yang K-C, Wang C-M, Lai J-S, Ko K-N, Chang P-Y, et al. Lead poisoning caused by contaminated Cordyceps, a Chinese herbal medicine: two case reports. Sci Total Environ. 1996;182(1-3):193-95.

48. Abdur R, Bhuiyan MAH. Arsenic contamination: Food toxicity and loca perception. International Journal of Scientific Research in Environmental Sciences. 2014;2(1):1-7.

49. A. Curry, Carrin G. Towards an Assessment of the Socioeconomic Impact of Arsenic Poisoning in Bangladesh. Organization WH, 2000. http://www.bvsde. ops-oms.org/bvsacd/who/poison.pdf.

50. Anderson K, Nisenblat V, Norman R. Lifestyle factors in people seeking infertility treatment - A review. Aust N Z J Obstet Gynaecol. 2010;50(1):8-20.

51. Sears ME, Kerr KJ, Bray RI. Arsenic, cadmium, lead, and mercury in sweat: a systematic review. Journal of environmental and public health. 2012;2012: 184745.

52. Genuis SJ, Birkholz D, Rodushkin I, Beesoon S. Blood, urine, and sweat (BUS) study: monitoring and elimination of bioaccumulated toxic elements. Arch Environ Contam Toxicol. 2011;61(2):344-57.

53. Omokhodion FO, Crockford GW. Sweat lead levels in persons with high blood lead levels: experimental elevation of blood lead by ingestion of lead chloride. Sci Total Environ. 1991;108(3):235-42.

54. Gavaler JS, Van Thiel DH, Lester R. Ethanol: a gonadal toxin in the mature rat of both sexes. Alcohol Clin Exp Res. 1980;4(3):271-6.

55. McKenzie PP, McClaran JD, Caudle MR, Fukuda A, Wimalasena J. Alcohol inhibits epidermal growth factor-stimulated progesterone secretion from human granulosa cells. Alcohol Clin Exp Res. 1995;19(6):1382-8.

56. Leach RE, Stachecki JJ, Armant DR. Development of in vitro fertilized mouse embryos exposed to ethanol during the preimplantation period: accelerated embryogenesis at subtoxic levels. Teratology. 1993;47(1):57-64.

57. Muti P, Trevisan M, Micheli A, Krogh V, Bolelli G, Sciajno R, et al. Alcohol consumption and total estradiol in premenopausal women. Cancer Epidemiol Biomark Prev. 1998;7(3):189-93.

58. Reichman ME, Judd JT, Longcope C, Schatzkin A, Clevidence BA, Nair $P P$, et al. Effects of alcohol consumption on plasma and urinary hormone concentrations in premenopausal women. J Natl Cancer Inst. 1993;85(9):722-7.

59. Alonso ML, Benedito JL, Miranda M, Castillo C, Hernandez J, Shore RF. Interactions between toxic and essential trace metals in cattle from a region with low levels of pollution. Arch Environ Contam Toxicol. 2002;42(2):165-72.

60. Shen YH, Chen CJ, Chuang HY. 0029 A Study of Blood Multi-element Concentrations in Lead-exposed and Non-exposed Workers. Occup Environ Med. 2014;71 Suppl 1:A61-2

61. lavicoli I, Fontana L, Bergamaschi A. The effects of metals as endocrine disruptors. J Toxicol Environ Health B Crit Rev. 2009;12(3):206-23.

62. Balabanič D, Rupnik M, Klemenčič AK. Negative impact of endocrinedisrupting compounds on human reproductive health. Reprod Fertil Dev. 2011;23(3):403-16.

63. CDC US. Interpreting and managing blood lead levels $<10$ microg/dL in children and reducing childhood exposures to lead: recommendations of CDC's Advisory Committee on Childhood Lead Poisoning Prevention. 2007. http://www.cdc.gov/mmwr/preview/mmwrhtml/rr5608a1.htm.

64. Basso O, Olsen J, Bisanti L, Karmaus W. The performance of several indicators in detecting recall bias. European Study Group on Infertility and Subfecundity. Epidemiology (Cambridge, Mass). 1997;8(3):269-74.

65. Czeizel AE, Petik D, Puho E. Smoking and alcohol drinking during pregnancy. The reliability of retrospective maternal self-reported information. Cent Eur J Public Health. 2004;12(4):179-83.
66. Güvenç $M$, Güven $H$, Karataş $F$, Aygün AD, Bektaş S. Low levels of selenium in miscarriage. J Trace Elem Exp Med. 2002;15(2):97-101.

67. Pathak P, Kapil U. Role of trace elements zinc, copper and magnesium during pregnancy and its outcome. Indian J Pediatr. 2004;71(11):1003-05.

68. Ministry of the Interior R.O.C. Life Tables for Republic of China Available from: [http://sowf.moi.gov.tw/stat/english/elife/elist.htm]. Assess Date: 31 January.

\section{Submit your next manuscript to BioMed Central and we will help you at every step:}

- We accept pre-submission inquiries

- Our selector tool helps you to find the most relevant journal

- We provide round the clock customer support

- Convenient online submission

- Thorough peer review

- Inclusion in PubMed and all major indexing services

- Maximum visibility for your research

Submit your manuscript at www.biomedcentral.com/submit
Biomed Central 